\section{RSP}

http://www.rsp.fsp.usp.br/
Revista de Saúde Pública

\title{
Adults at high-risk of severe coronavirus disease-2019 (Covid-19) in Brazil
}

\author{
Leandro F. M. Rezende' (iD, Beatriz Thome' (iD, Mariana Cabral Schveitzer' (iD, Paulo Roberto \\ Borges de Souza-Júnior" iD, Célia Landmann Szwarcwald" iD \\ ' Universidade Federal de São Paulo. Escola Paulista de Medicina. Departamento de Medicina Preventiva. São \\ Paulo, SP, Brasil \\ " Fundação Instituto Oswaldo Cruz. Instituto de Comunicação e Informação Científica e Tecnológica em Saúde. \\ Rio de Janeiro, RJ, Brasil
}

\section{ABSTRACT}

OBJECTIVE: To estimate the proportion and total number of the general adult population who may be at higher risk of severe Covid-19 in Brazil.

METHODS: We included 51,770 participants from a nationally representative, household-based health survey (PNS) conducted in Brazil. We estimated the proportion and number of adults ( $\geq 18$ years) at risk of severe Covid-19 by sex, educational level, race/ethnicity, and state based on the presence of one or more of the following risk factors: age $\geq 65$ years or medical diagnosis of cardiovascular disease, diabetes, hypertension, chronic respiratory disease, cancer, stroke, chronic kidney disease and moderate to severe asthma, smoking status, and obesity.

RESULTS: Adults at risk of severe Covid-19 in Brazil varied from 34.0\% (53 million) to 54.5\% (86 million) nationwide. Less-educated adults present a 2-fold higher prevalence of risk factors compared to university graduated. We found no differences by sex and race/ethnicity. São Paulo, Rio de Janeiro, Minas Gerais, and Rio Grande do Sul were the most vulnerable states in absolute and relative terms of adults at risk.

\section{Correspondence:}

Leandro F. M. Rezende

Universidade Federal de São

Paulo. Escola Paulista de Medicina.

Departamento de Medicina Preventiva

Rua Botucatu, 740, $4^{\circ}$ Andar sala 457 04023-062 São Paulo, SP, Brasil

E-mail: leandro.rezende@unifesp.br

Received: Apr 28, 2020

Approved: Apr 28, 2020

How to cite: Rezende LFM, Thome B, Schveitzer MC, Souza-Junior PRB, Szwarcwald CL. Adults at high-risk of severe coronavirus disease-2019 (Covid-19) in Brazil. Rev Saude Publica. 2020;54:50.

Copyright: This is an open-access article distributed under the terms of the Creative Commons Attribution License, which permits unrestricted use, distribution, and reproduction in any medium, provided that the original author and source are credited.

CONCLUSIONS: Proportion and total number of adults at risk of severe Covid-19 are high in Brazil, with wide variation across states and adult subgroups. These findings should be considered while designing and implementing prevention measures in Brazil. We argue that these results support broad social isolation measures, particularly when testing capacity for SARS-CoV-2 is limited.

DESCRIPTORS: Risk Groups. Coronavirus Infections, epidemiology. Socioeconomic Factors. Patient Care Planning. 


\section{INTRODUCTION}

The World Health Organization (WHO) suggests that most people infected with the virus may develop mild or uncomplicated (80\%) coronavirus disease 2019 (Covid-19), while the remaining $20 \%$ may develop its severe variation, requiring hospitalization (14\%) or intensive care unit $(6 \%)^{1}$. Established risk factors for severe disease among inpatients with Covid-19 in China included older age $\mathrm{e}^{2,3}$ and serious medical conditions such as cardiovascular disease $\mathrm{e}^{2-4}$, diabetes $^{2-4}$, chronic respiratory disease (in particular chronic obstructive pulmonary disease - COPD) $)^{2}$, hypertension ${ }^{2,4}$, cancer ${ }^{2,5}$, and cerebrovascular disease ${ }^{3,4}$. Recent findings from United States (US) and Europe confirmed these risk factors and proposed new ones, such as chronic kidney disease, obesity, asthma and smoking ${ }^{6-9}$.

The emergence of a highly transmissible pathogen ${ }^{10}$ in a completely susceptible population has resulted in an exponential growth of new cases worldwide and a wide dissemination across the globe. As of April 12, 2020, the number of SARS-CoV-2 infections was above 1.8 million, reported in 185 countries/regions of the world ${ }^{11}$. High- and low-income regions are already facing overload of health facilities and facing scarcity of resources to fight the pandemic. In lower resource settings, countries have a short time to prepare prevention and management strategies, including the identification of high-risk populations and regions within countries.

Herein, we propose a calculation of the proportion and total number of the general adult population who may be at higher risk for severe Covid-19, based on routinely collected data from a nationwide, household-based survey in Brazil. We argue that this method could be easily and rapidly applied within and across countries in order to craft tailored prevention strategies such as social isolation.

\section{METHODS}

We obtained data from the most recent representative, household-based survey conducted in Brazil, the National Health Survey (PNS, 2013 - Pesquisa Nacional de Saúde), carried out by the Ministry of Health in partnership with the Brazilian Institute of Geography and Statistics (IBGE). The PNS enrolled 62,202 adults who responded to a comprehensive questionnaire about several health-related issues. In this study, we included 51,770 participants who responded to the questionnaire about medical diagnosis and lifestyle risk factors, and had their weight and height measured. Further details about PNS have been described elsewhere ${ }^{12}$.

\section{Risk Factors for Severe Covid-19}

We included risk factors for severe Covid-19 based on currently available information from clinical studies and expertise ${ }^{2-9}$, and for which exposure data were available in the $\mathrm{PNS}^{12}$. Age and medical diagnosis of cardiovascular disease, diabetes, hypertension, chronic respiratory disease, cancer, stroke, chronic kidney disease and asthma were assessed. We also obtained time (in years) since cancer diagnosis and treatment/medication use for chronic kidney disease (e.g. dialysis) and asthma to match definitions from the literature (e.g. moderate to severe asthma). Information about age, smoking status and measured body mass index (BMI) were also obtained/estimated.

Prevalence of one or more risk factors for severe Covid-19 was estimated using two criteria (Table 1). Criterion 1 included first identified and established risk factors for severe Covid-19 such as age $\geq 65$ years or medical diagnosis of cardiovascular disease, diabetes, hypertension, chronic respiratory disease, cancer or stroke. Although $\geq 60$ years have been used to define older adults in Brazil, herein we considered $\geq 65$ years to match the definition of risk factors for Covid-19 obtained from the literature and allow comparisons with other publications ${ }^{2-9}$. Criterion 2 additionally included diagnosis of chronic kidney 
Table 1. Definition of risk factors for severe Covid-19 according to two different proposed criteria.

\begin{tabular}{|c|c|c|c|}
\hline \multirow{2}{*}{ Risk factors } & \multirow{2}{*}{ Definition } & \multicolumn{2}{|c|}{ Presence of risk factor for severe Covid-19 } \\
\hline & & Criterion 1 & Criterion 2 \\
\hline Age & in years & $\geq 65$ years & $\geq 65$ years \\
\hline Cardiovascular disease & $\begin{array}{l}\text { Has a doctor ever diagnosed you with } \\
\text { a heart disease such as infarction, } \\
\text { angina, heart failure or other? }\end{array}$ & Yes & Yes \\
\hline Diabetes & $\begin{array}{l}\text { Has a doctor ever diagnosed you } \\
\text { with diabetes? }\end{array}$ & Yes & Yes \\
\hline Hypertension & $\begin{array}{l}\text { Has a doctor ever diagnosed you } \\
\text { with hypertension (high blood } \\
\text { pressure)? }\end{array}$ & Yes & Yes \\
\hline Chronic respiratory disease & $\begin{array}{l}\text { Has a doctor already diagnosed } \\
\text { you with any lung disease such as } \\
\text { pulmonary emphysema, chronic } \\
\text { bronchitis, or COPD (Obstructive } \\
\text { Pulmonary Disease Chronic)? }\end{array}$ & Yes & Yes \\
\hline \multirow{2}{*}{ Cancer } & $\begin{array}{l}\text { Has any doctor ever diagnosed you } \\
\text { with cancer (excluding skin cancer)? }\end{array}$ & Yes & Yes \\
\hline & $\begin{array}{l}\text { How many years ago since your } \\
\text { cancer diagnosis? }\end{array}$ & $<5$ years & $<5$ years \\
\hline Stroke & $\begin{array}{c}\text { Has any doctor ever diagnosed you } \\
\text { with stroke? }\end{array}$ & Yes & Yes \\
\hline Obesity & Measured body mass index & No & $\geq 30 \mathrm{~kg} / \mathrm{m}^{2}$ \\
\hline Smoking & Current smoker & No & $\begin{array}{c}\text { Yes } \\
\text { (daily or less than daily) }\end{array}$ \\
\hline \multirow[b]{2}{*}{ Chronic kidney disease } & $\begin{array}{l}\text { Has any doctor ever diagnosed you } \\
\text { with chronic kidney disease? }\end{array}$ & No & Yes \\
\hline & $\begin{array}{l}\text { What do you currently do or } \\
\text { have done because of the chronic } \\
\text { kidney disease? }\end{array}$ & No & $\begin{array}{l}\text { Hemodialysis, } \\
\text { peritoneal dialysis, took } \\
\text { medication, underwent } \\
\text { a kidney transplant }\end{array}$ \\
\hline \multirow[t]{2}{*}{ Moderate to severe asthma } & $\begin{array}{c}\text { Has any doctor ever diagnosed } \\
\text { you with asthma (or asthmatic } \\
\text { bronchitis)? }\end{array}$ & No & Yes \\
\hline & $\begin{array}{l}\text { What do you currently do because } \\
\text { of asthma? }\end{array}$ & No & $\begin{array}{l}\text { Use of inhalers, aerosol } \\
\text { or tablets }\end{array}$ \\
\hline
\end{tabular}

disease and moderate to severe asthma, smoking status (current smokers) and obesity $\left(\mathrm{BMI} \geq 30 \mathrm{~kg} / \mathrm{m}^{2}\right)$. Criterion 2 was used to provide a higher sensitivity for the proportion of adults at risk of severe illness. Denominator for both criteria $1(n=52,511)$ and $2(n=51,770)$ included all participants with complete questionnaires. We also estimated the sum of all risk factors for severe illness ( $0,1,2,3+$ risk factors).

\section{Sociodemographic Covariates}

Information on covariates including sex, race/ethnicity, educational level, and Brazilian state (26 states and the Federative District) were obtained to describe the proportion of adults at risk of severe Covid-19 by population strata. We also retrieved the total projected number of the Brazilian adult population ( $\geq 18$ years) in 2020 by sex and state from the IBGE ${ }^{13}$.

\section{Statistical Analysis}

We estimated the prevalence and 95\% confidence intervals of adults at risk for severe Covid-19 (Criterion 1 and Criterion 2) by sex, education, race/ethnicity and Brazilian state. We performed sensitivity analyses for prevalence by considering two other definitions for older adults ( $\geq 60$ years and $\geq 70$ years). In order to obtain the total number of adults at risk of severe illness, we applied the prevalence to the number of adult's population ( $\geq 18$ years) by sex and state. The sample design was considered for all analyses using the survey prefix command (svy) in Stata version 15.0. 


\section{RESULTS}

Participants characteristics and risk factors for severe illness are presented by age group (Table 2). Compared with younger participants, older adults ( $\geq 65$ years) were less educated, more likely women, white and presented higher prevalence of risk factors for severe Covid-19, except for smoking. Prevalence of one or more risk factors for severe illness was $47.3 \%$ in younger vs $75.9 \%$ in older adults.

Proportion and total number of adults at risk for severe Covid-19 in Brazil varied from $34.0 \%$ (53 million adults) to $54.5 \%$ (86 million adults) (Table 3). Overall, $46 \%$ of the sample presented no risk factor, $30.0 \%$ with one, $15.0 \%$ with two, and $9 \%$ with 3 or more risk factors for severe illness. Sensitivity analyses considering older adults $\geq 60$ years and $\geq 70$ years suggested that prevalence could vary from $36.7 \%-56.2 \%$ to $32.3 \%-53.3 \%$, respectively (Table 4).

Table 2. Characteristics and risk factors for severe Covid-19 by age group in Brazil, PNS 2013

\begin{tabular}{|c|c|c|c|}
\hline \multirow{2}{*}{ Characteristics } & \multicolumn{2}{|c|}{ Age groups } & \multirow{2}{*}{ Total } \\
\hline & $<65$ years & $\geq 65$ years & \\
\hline Number of participants & 23.838 & 27.932 & 51.770 \\
\hline Mean age, years (se) & $39.7(11.4)$ & $73.5(14.1)$ & $44.3(15.0)$ \\
\hline \multicolumn{4}{|l|}{$\operatorname{Sex}(\%)$} \\
\hline Men & 45.4 & 42.9 & 45.0 \\
\hline \multicolumn{4}{|l|}{ Education (\%) } \\
\hline None or incomplete primary education & 15.1 & 67.0 & 22.2 \\
\hline Complete primary or incomplete secondary education & 27.2 & 14.0 & 25.4 \\
\hline $\begin{array}{l}\text { Complete secondary education or incomplete } \\
\text { undergraduate course }\end{array}$ & 42.7 & 10.3 & 38.3 \\
\hline University Graduate & 15.0 & 8.7 & 14.1 \\
\hline \multicolumn{4}{|l|}{ Race/ethnicity (\%) } \\
\hline White & 48.3 & 55.9 & 49.4 \\
\hline Non-white & 51.7 & 44.1 & 50.6 \\
\hline \multicolumn{4}{|l|}{ Risk factors for Severe Covid-19 (\%) } \\
\hline Cardiovascular disease & 3.4 & 13.0 & 4.7 \\
\hline Diabetes & 5.1 & 20.7 & 7.2 \\
\hline Chronic respiratory disease & 1.5 & 4.4 & 1.9 \\
\hline Hypertension & 18.8 & 55.3 & 23.7 \\
\hline Cancer & 0.6 & 2.2 & 0.8 \\
\hline Stroke & 1.0 & 6.1 & 1.7 \\
\hline Obesity (BMI $\geq 30$ kg/m²) & 22.0 & 22.7 & 22.1 \\
\hline Smoking & 14.6 & 9.6 & 13.9 \\
\hline Chronic kidney disease & 0.7 & 2.0 & 0.9 \\
\hline Moderate to severe asthma & 1.5 & 1.7 & 1.5 \\
\hline \multicolumn{4}{|l|}{ Number of risk factors for severe Covid-19* (\%) } \\
\hline None & 52.7 & 24.1 & 48.8 \\
\hline 1 & 30.9 & 35.1 & 31.5 \\
\hline 2 & 12.0 & 25.2 & 13.8 \\
\hline $3+$ & 4.4 & 15.6 & 5.9 \\
\hline
\end{tabular}

SE: standard error

* Diagnosis of cardiovascular disease, diabetes, chronic respiratory disease, hypertension, cancer $(<5$ years of diagnosis), stroke, obesity (BMI $\geq 30 \mathrm{~kg} / \mathrm{m}^{2}$ ), current smoking, chronic kidney disease (diagnosis and under hemodialysis, peritoneal dialysis, taking medication or did a kidney transplant), moderate to severe asthma (diagnosis and taking inhalers, aerosol or tablets) 
Table 3. Prevalence of one or more risk factor for severe Covid-19 among the Brazilian general adult population by risk criteria and sociodemographic characteristics, PNS 2013

\begin{tabular}{|c|c|c|c|c|}
\hline \multirow{3}{*}{ Characteristics } & \multicolumn{4}{|c|}{ Prevalence of one or more risk factors for severe Covid-19 } \\
\hline & \multicolumn{2}{|c|}{ Criterion $1(n=52,511)$} & \multicolumn{2}{|c|}{ Criterion $2(n=51,770)$} \\
\hline & Prevalence $(\%)$ & $95 \% \mathrm{Cl}$ & Prevalence (\%) & $95 \% \mathrm{Cl}$ \\
\hline Total & 34.0 & $33.2-34.7$ & 54.4 & $53.6-55.2$ \\
\hline \multicolumn{5}{|l|}{ Sex } \\
\hline Men & 31.6 & $30.5-32.8$ & 53.3 & $52.1-54.5$ \\
\hline Women & 35.9 & $34.9-36.8$ & 55.4 & $54.3-56.4$ \\
\hline \multicolumn{5}{|l|}{ Education } \\
\hline $\begin{array}{l}\text { None or incomplete primary } \\
\text { education }\end{array}$ & 66.3 & $64.7-67.9$ & 80.2 & 78.9-81.4 \\
\hline $\begin{array}{l}\text { Complete primary or incomplete } \\
\text { secondary education }\end{array}$ & 30.5 & $29.2-31.9$ & 55.0 & $53.5-56.5$ \\
\hline $\begin{array}{l}\text { Complete secondary education or } \\
\text { incomplete undergraduate course }\end{array}$ & 20.4 & $19.4-21.4$ & 42.2 & $40.9-43.6$ \\
\hline University Graduate & 27.0 & $25.1-29.1$ & 46.1 & $44.1-48.3$ \\
\hline \multicolumn{5}{|l|}{ Race/ethnicity } \\
\hline White & 34.9 & $33.8-36.0$ & 55.0 & $53.9-56.2$ \\
\hline Non-white & 33.1 & $21.1-34.0$ & 53.9 & $52.8-54.9$ \\
\hline
\end{tabular}

Criterion 1: age $\geq 65$ years or diagnosis of cardiovascular disease, diabetes, chronic respiratory disease, hypertension, cancer $(<5$ years of diagnosis), or stroke

Criterion 2: additionally, obesity (BMI $\geq 30 \mathrm{~kg} / \mathrm{m}^{2}$ ), current smoking, chronic kidney disease (diagnosis and under Hemodialysis, peritoneal dialysis, taking medication or did a kidney transplant), moderate to severe asthma (diagnosis and taking inhalers, aerosol or tablets)

Table 4. Sensitivity analysis: prevalence of one or more risk factors for severe Covid-19 among the Brazilian general adult population by risk criteria, definitions of older age and sociodemographic characteristics in Brazil, PNS 2013.

\begin{tabular}{|c|c|c|c|c|c|c|c|c|}
\hline \multirow{4}{*}{ Characteristics } & \multicolumn{8}{|c|}{ Risk factors for severe Covid-19 } \\
\hline & \multicolumn{4}{|c|}{ Criterion $1(n=52,511)$} & \multicolumn{4}{|c|}{ Criterion $2(n=51,770)$} \\
\hline & \multicolumn{2}{|c|}{$\begin{array}{c}\text { Older age defined as } \\
\geq 60 \text { years }\end{array}$} & \multicolumn{2}{|c|}{$\begin{array}{c}\text { Older age defined as } \\
\geq 70 \text { years }\end{array}$} & \multicolumn{2}{|c|}{$\begin{array}{c}\text { Older age defined as } \\
\geq 60 \text { years }\end{array}$} & \multicolumn{2}{|c|}{$\begin{array}{c}\text { Older age defined as } \\
\geq 70 \text { years }\end{array}$} \\
\hline & $\begin{array}{l}\text { Prevalence } \\
\quad(\%)\end{array}$ & $95 \% \mathrm{Cl}$ & $\begin{array}{l}\text { Prevalence } \\
\quad(\%)\end{array}$ & $95 \% \mathrm{Cl}$ & $\begin{array}{l}\text { Prevalence } \\
\quad(\%)\end{array}$ & $95 \% \mathrm{Cl}$ & $\begin{array}{l}\text { Prevalence } \\
\quad(\%)\end{array}$ & $95 \% \mathrm{Cl}$ \\
\hline Total & 36.7 & $36.0-37.5$ & 32.3 & $31.6-33.0$ & 56.2 & $55.3-57.0$ & 53.3 & $52.5-54.0$ \\
\hline \multicolumn{9}{|l|}{ Sex } \\
\hline Men & 34.5 & $33.3-35.6$ & 30.0 & $28.9-31.1$ & 54.9 & $53.7-56.1$ & 52.2 & $51.0-53.4$ \\
\hline Women & 38.6 & $37.6-39.5$ & 34.2 & $33.3-35.1$ & 57.2 & $56.1-58.2$ & 54.2 & $53.2-55.2$ \\
\hline \multicolumn{9}{|l|}{ Education } \\
\hline None or incomplete primary & 72.0 & $70.4-73.4$ & 62.2 & $60.5-63.8$ & 83.4 & $82.3-84.6$ & 77.5 & $76.2-78.8$ \\
\hline $\begin{array}{l}\text { Complete primary or } \\
\text { incomplete secondary }\end{array}$ & 32.2 & $30.9-33.6$ & 29.3 & $28.0-30.6$ & 56.2 & $54.6-57.7$ & 54.1 & $52.5-55.6$ \\
\hline $\begin{array}{l}\text { Complete secondary or } \\
\text { incomplete university }\end{array}$ & 22.1 & $21.1-23.2$ & 19.8 & $18.8-20.8$ & 43.4 & $42.0-44.7$ & 41.8 & $40.4-43.2$ \\
\hline University Graduate & 30.0 & $28.0-32.1$ & 25.6 & $23.7-27.5$ & 48.1 & $45.9-50.2$ & 45.1 & $43.0-47.2$ \\
\hline \multicolumn{9}{|l|}{ Race/ethnicity } \\
\hline White & 38.0 & $36.9-39.2$ & 33.1 & $32.0-34.2$ & 57.0 & $55.8-58.2$ & 53.8 & $52.6-54.9$ \\
\hline Non-white & 35.5 & $34.5-36.5$ & 31.6 & $30.6-32.5$ & 55.3 & $54.3-56.3$ & 52.8 & $51.8-53.9$ \\
\hline
\end{tabular}

Criterion 1: age group or diagnosis of cardiovascular disease, diabetes, chronic respiratory disease, hypertension, cancer ( $<5$ years of diagnosis), or stroke; Criterion 2: additionally obesity (BMI $\geq 30 \mathrm{~kg} / \mathrm{m}^{2}$ ), current smoking, chronic kidney disease (diagnosis and under hemodialysis, peritoneal dialysis, taking medication or did a kidney transplant), moderate to severe asthma (diagnosis and taking inhalers, aerosol or tablets).

Proportion of adults at risk for severe Covid-19 was 2-fold higher in less educated participants compared with university graduated. We found no differences in prevalence estimates by sex and race/ethnicity (Table 3). Estimates varied widely across states, with higher prevalence 
in the South and Southeast regions of the country (Figure). The highest prevalence was $39.5 \%-58.4 \%$ in Rio Grande do Sul, followed by $36.0-55.8 \%$ in Rio de Janeiro and $35.6 \%-58.2 \%$ in São Paulo. The lowest prevalence was found in Amapá (23.4\%-45.9\%), followed by Roraima (25.0\%-48.6\%) and Amazonas (25.1\%-48.7\%). The highest number of adults at risk of severe illness was found in São Paulo (17-21 million), Minas Gerais (6-9 million) and Rio de Janeiro (5-7 million) (Table 5).

\section{Criterion $1^{\text {a }}$}

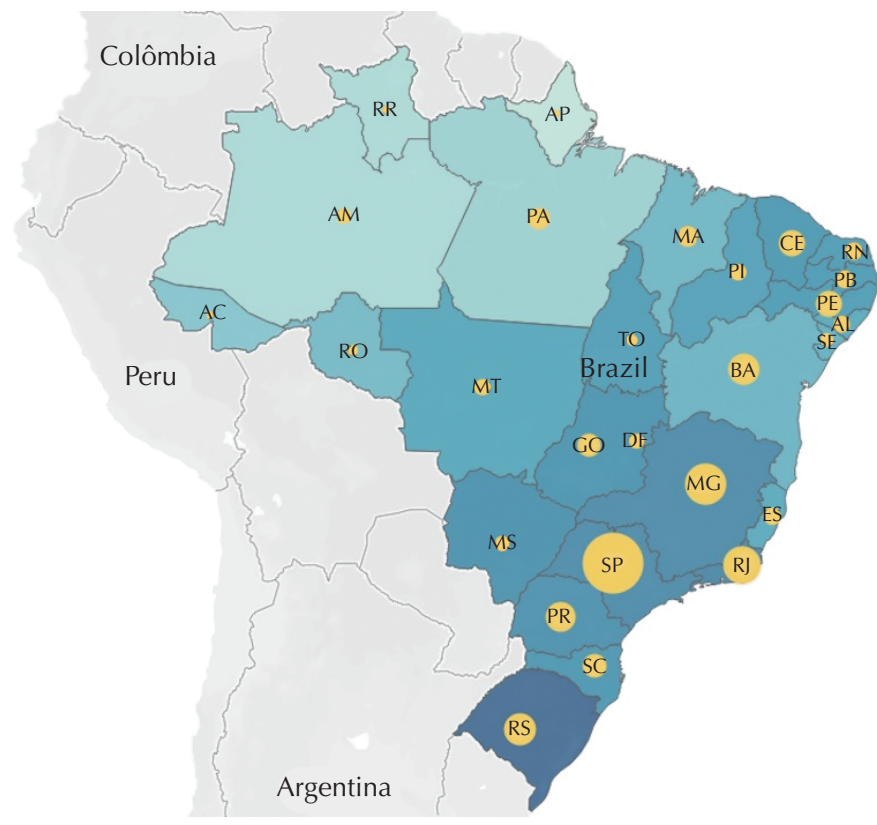

Atlantic Ocean

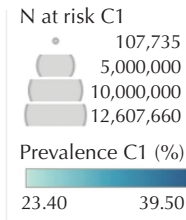

\section{Criterion $2^{\text {b }}$}

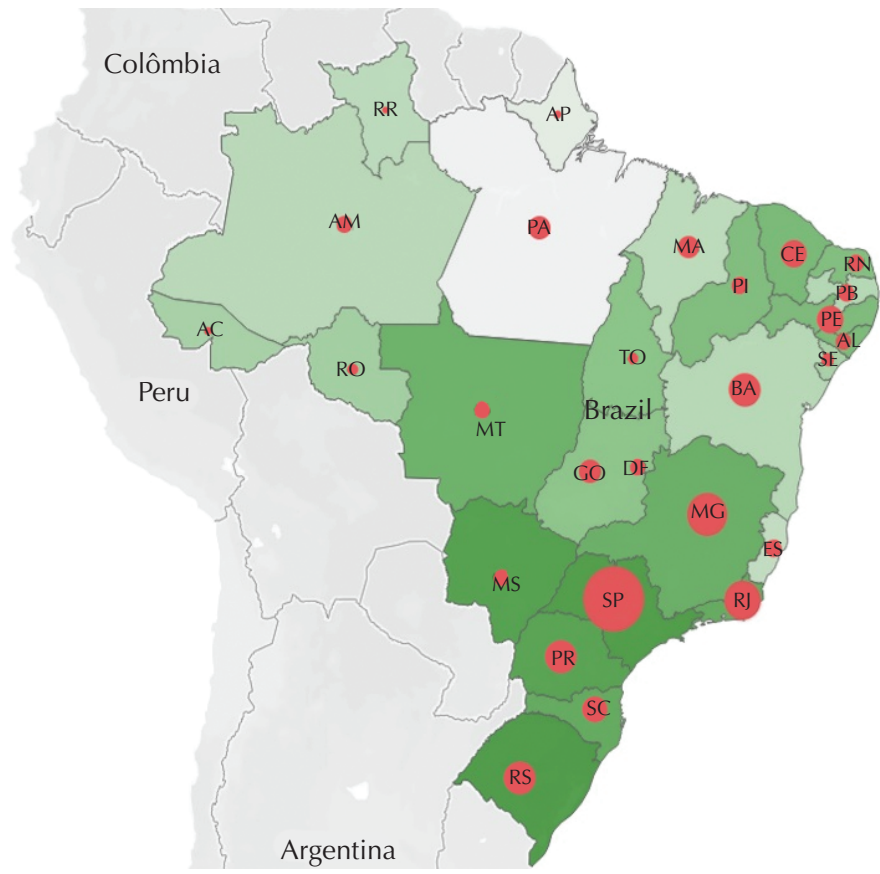


Table 5. Prevalence of one or more risk factors for severe Covid-19 among the Brazilian general adult population by risk criteria and Brazilian states, PNS 2013.

\begin{tabular}{|c|c|c|c|c|c|c|c|}
\hline \multirow{3}{*}{ Brazilian States } & \multirow{3}{*}{$\begin{array}{l}\text { Adult population } \\
\quad \text { ( } \geq 18 \text { years) }\end{array}$} & \multicolumn{6}{|c|}{ Prevalence of one or more risk factors for severe Covid-19, \% } \\
\hline & & \multicolumn{3}{|c|}{ Criterion $1(n=52,511)$} & \multicolumn{3}{|c|}{ Criterion $2(n=51,770)$} \\
\hline & & Prevalence $(\%)$ & $95 \% \mathrm{Cl}$ & $\mathrm{N}$ at risk & Prevalence $(\%)$ & $95 \% \mathrm{Cl}$ & $\mathrm{N}$ at risk \\
\hline Brazil & $158,255,554$ & 34.0 & $33.2-34.7$ & $53,806,888$ & 54.4 & $53.6-55.2$ & $86,091,021$ \\
\hline \multicolumn{8}{|l|}{ Brazilian States } \\
\hline Rondônia & $1,296,218$ & 29.6 & $26.7-32.7$ & 383,681 & 50.3 & $47.3-53.2$ & 651,998 \\
\hline Acre & 581,754 & 28.1 & $25.3-31.0$ & 163,473 & 50.0 & $46.8-53.2$ & 290,877 \\
\hline Amazonas & $2,769,201$ & 25.1 & $22.6-27.8$ & 695,069 & 48.7 & $45.7-51.7$ & $1,348,601$ \\
\hline Roraima & 430,939 & 25.0 & $22.3-27.9$ & 107,735 & 48.6 & $45.0-52.2$ & 209,436 \\
\hline Pará & $5,971,477$ & 26.2 & $23.2-29.3$ & $1,564,527$ & 45.2 & $41.8-48.7$ & $2,699,108$ \\
\hline Amapá & 570,298 & 23.4 & $20.2-26.9$ & 133,450 & 45.9 & $41.6-50.3$ & 261,767 \\
\hline Tocantins & $1,125,023$ & 33.1 & $29.0-37.6$ & 372,383 & 52.2 & $48.7-55.7$ & 587,262 \\
\hline Maranhão & $4,873,279$ & 30.0 & $26.3-34.0$ & $1,461,984$ & 48.5 & $43.9-53.0$ & $2,363,540$ \\
\hline Piauí & $2,383,425$ & 32.7 & $29.4-36.1$ & 779,380 & 53.0 & $49.6-56.3$ & $1,263,215$ \\
\hline Ceará & $6,788,403$ & 33.8 & $31.0-36.7$ & $2,294,480$ & 53.7 & $50.8-56.6$ & $3,645,372$ \\
\hline Rio Grande do Norte & $2,632,403$ & 33.2 & $30.2-36.3$ & 873,958 & 52.9 & $49.7-56.1$ & $1,392,541$ \\
\hline Paraiba & $2,984,647$ & 33.4 & $30.6-36.3$ & 996,872 & 49.0 & $46.0-51.9$ & $1,462,477$ \\
\hline Pernambuco & $7,035,040$ & 33.2 & $30.7-35.8$ & $2,335,633$ & 53.4 & $50.8-55.9$ & $3,756,711$ \\
\hline Alagoas & $2,377,983$ & 31.7 & $28.6-35.0$ & 753,821 & 53.5 & $49.7-57.3$ & $1,272,221$ \\
\hline Sergipe & $1,688,955$ & 30.8 & $28.0-33.8$ & 520,198 & 50.0 & $46.7-53.2$ & 844,478 \\
\hline Bahia & $11,044,986$ & 30.3 & $26.8-34.1$ & $3,346,631$ & 48.9 & $44.8-53.0$ & $5,400,998$ \\
\hline Minas Gerais & $16,425,183$ & 35.6 & $33.1-38.2$ & $5,847,365$ & 55.1 & $52.0-58.2$ & $9,050,276$ \\
\hline Espírito Santo & $3,047,439$ & 31.5 & $27.6-35.6$ & 959,943 & 48.1 & $43.6-52.7$ & $1,465,818$ \\
\hline Rio de Janeiro & $13,419,464$ & 36.0 & $33.8-38.1$ & $4,831,007$ & 55.8 & $53.6-58.0$ & $7,488,061$ \\
\hline São Paulo & $35,414,776$ & 35.6 & $33.7-37.4$ & $12,607,660$ & 58.2 & $56.2-60.2$ & $20,611,400$ \\
\hline Paraná & $8,736,014$ & 34.9 & $31.7-38.2$ & $3,048,869$ & 57.1 & $53.3-60.9$ & $4,988,264$ \\
\hline Santa Catarina & $5,578,842$ & 34.1 & $30.2-38.2$ & $1,902,385$ & 55.9 & $51.6-60.1$ & $3,118,573$ \\
\hline Rio Grande do Sul & $8,902,263$ & 39.5 & $36.8-42.3$ & $3,516,394$ & 58.4 & $55.6-61.1$ & $5,198,922$ \\
\hline Mato Grosso do Sul & $2,045,881$ & 34.7 & $31.6-37.8$ & 709,921 & 57.6 & $54.5-60.7$ & $1,178,427$ \\
\hline Mato Grosso & $2,543,642$ & 31.9 & $28.9-35.1$ & 811,422 & 54.8 & $51.9-57.6$ & $1,393,916$ \\
\hline Goiás & $5,277,383$ & 34.4 & $31.5-37.4$ & $1,815,420$ & 52.0 & $49.1-54.9$ & $2,744,239$ \\
\hline Distrito Federal & $2,310,636$ & 29.9 & $27.3-32.5$ & 690,880 & 49.2 & $46.3-52.1$ & $1,136,833$ \\
\hline
\end{tabular}

$\mathrm{N}$ at risk: number of adults ( $\geq 18$ years) at risk of severe Covid-19

Criterion 1: age $\geq 65$ years or diagnosis of cardiovascular disease, diabetes, chronic respiratory disease, hypertension, cancer $(<5$ years of diagnosis), or stroke; Criterion 2: additionally obesity $\left(\mathrm{BMI} \geq 30 \mathrm{~kg} / \mathrm{m}^{2}\right.$ ), current smoking, chronic kidney disease (diagnosis and under Hemodialysis, peritoneal dialysis, taking medication or did a kidney transplant), moderate to severe asthma (diagnosis and taking inhalers, aerosol or tablets)

\section{DISCUSSION}

In this study, we estimated that a third (53 million) to over a half (86 million) of Brazilian adults present at least one risk factor for severe Covid-19. Our findings point to high prevalence of serious medical conditions in younger, but mostly, among older adults. Less educated adults present 2-fold higher prevalence of risk factors compared with university graduated. São Paulo, Rio de Janeiro, Minas Gerais and Rio Grande do Sul were the most vulnerable states in absolute and relative terms of adults at high-risk. Contrasts between South and Southeast vs North and Northeast regions might be due to different age structure, prevalence of health condition and/or access to medical diagnosis and care.

Estimating the proportion of the population at risk for severe Covid-19 within and across countries is key to improve prevention measures. However, to our knowledge, these estimates are still sparse worldwide. In the US, it was estimated that four in ten (37.6\%) adults $\geq 18$ years may be at high-risk of severe Covid-19 ${ }^{14}$. During the pandemic, time is 
limited and hence the use of existing health information to support countries' response is imperative. These findings and methods to identify high-risk settings may be useful to plan and manage prevention strategies in Brazil and other low- to middle-income settings with routinely collected data from population-based surveys, but limited testing capacity for SARS-CoV-2.

The understanding of risk factors for severe Covid-19 has so far supported the implementation of prevention strategies. It is interesting to note that non-communicable diseases such as cardiovascular disease, cancer, respiratory diseases, and diabetes, which accounts for most of deaths globally ${ }^{15}$, play a role on worsening the impact of the Covid-19 pandemic. Since isolation of infected cases and contact tracing alone will not likely suffice to control the pandemic ${ }^{16}$, countries have largely implemented social isolation measures. The combination of different interventions such as case isolation, social distancing of the entire population, household quarantine, school closure and, ultimately, complete lockdown is predicted to have significant impact on transmission ${ }^{17}$. Protecting the groups that are most at risk ${ }^{18}$, such as older adults and people with comorbidities, by widely and temporarily refraining from engaging in social contact, remains imperative. As knowledge on the clinical course of Covid-19 advances, the understanding of risk factors for severe disease will be improved, and so will the estimates of most-at-risk populations.

Our results have some limitations. Prevalence of risk factors for severe Covid-19 is likely underestimated due to self-reported medical diagnosis of comorbidities and smoking status. Underlying diseases have been associated with poorer prognosis among inpatients with Covid-19, but some people may have lower risk due to well-controlled blood pressure and serum glucose, for instance, which may have overestimated the proportion and number of adults at risk. Undiagnosed, asymptomatic diseases such as diabetes and hypertension are concerns, especially in low-income settings. This may partially explain differences of adults at risk between Brazilian states. Estimates considered the same weight for all risk factors assessed, which may not be applicable. Furthermore, other known risk factors for severe Covid-19 such as living in a nursing home or long-term care facility, and immunosuppression could not be captured in our study. Lastly, risk factors information date from 2013, the most recent representative, household-based health survey of Brazilian adults. The proportion of older adults has increased in Brazil in the past seven years, as well as the prevalence of obesity and other non-communicable diseases ${ }^{19}$, which may have underestimated our estimates. On the other hand, the prevalence of tobacco smoking has decreased, which may have overestimated the adults at risk of severe Covid-19.

In conclusion, proportion and total number of adults at risk of severe Covid-19 is high in Brazil, with wide variation across states and adult subgroups. These findings should be considered while designing and implementing prevention measures. We argue that these results support broad social isolation measures, particularly while testing capacity for SARS-CoV-2 is limited.

\section{REFERENCES}

1. Novel Coronavirus Pneumonia Emergency Response Epidemiology Team. [The epidemiological characteristics of an outbreak of 2019 novel coronavirus diseases (COVID-19) - China]. Zhonghua Liu Xing Bing Xue Za Zhi. 2020;41(2):145-51. Chinese. https://doi.org/10.3760/cma.j.issn.0254-6450.2020.02.003

2. Wu Z, McGoogan JM. Characteristics of and important lessons from the coronavirus disease 2019 (COVID-19) outbreak in China: summary of a report of 72314 cases from the Chinese Center for Disease Control and Prevention [published online ahead of print, 2020 Feb 24]. JAMA. 2020. https://doi.org/doi:10.1001/jama.2020.2648

3. Du RH, Liang LR, Yang CQ, Wang W, Cao TZ, Li M, et al. Predictors of mortality for patients with COVID-19 Pneumonia caused by SARS-CoV-2: a prospective cohort study [published online ahead of print, 2020 Apr 9]. Eur Respir J. 2020 https://doi.org/10.1183/13993003.00524-2020 
4. Wang D, Hu B, Hu C, Zu F, Liu X, Zhang J, et al. Clinical characteristics of 138 hospitalized patients with 2019 novel coronavirus-infected pneumonia in Wuhan, China [published online ahead of print, 2020 Feb 7]]. JAMA. 2020;323(11):1061-9. https://doi.org/10.1001/jama.2020.1585

5. Liang W, Guan W, Chen R, Wang W, Li J, Xu K, et al. Cancer patients in SARS-CoV-2 infection: a nationwide analysis in China. Lancet Oncol. 2020.21(3):335-7. https://doi.org/10.1016/S1470-2045(20)30096-6

6. Grasselli G, Zangrillo A, Zanella A, Antonelli M, Cabrini L, Castelli A, et al. Baseline characteristics and outcomes of 1591 patients infected with SARS-CoV-2 admitted to ICUS of the Lombardy Region, Italy [published online ahead of print]. JAMA. 2020;323(16):1574-1581. https://doi.org/10.1001/jama.2020.5394

7. Centers for Disease Control and Prevention - CDC COVID-19 Response Team. Preliminary estimates of the prevalence of selected underlying health conditions among patients with Coronavirus Disease 2019 - United States, February 12-March 28, 2020. MMWR Morb Mortal Wkly Rep. 2020;69(13):382-6. https://doi.org/10.15585/mmwr.mm6913e2

8. COVID-19 Surveillance Group. Characteristics of COVID-19 patients dying in Italy: report based on available data on March 20 $0^{\text {th }}, 2020$. Rome (ITA): Istituto Superiore di Sanitá; 2020 [cited 2020 Apr 28]. Available from: https://www.epicentro.iss.it/coronavirus/bollettino/ReportCOVID-2019_20_marzo_eng.pdf

9. Leung JM, Yang CX, Tam A, Shaipanichi T, Hackett TL, Singhera GK, et al. ACE-2 expression in the small airway epithelia of smokers and COPD patients: implications for COVID-19 [published online ahead of print, 2020 Apr 8]. Eur Respir J. 2020. https://doi.org/10.1183/13993003.00688-2020

10. World Health Organization. Report of the WHO-China Joint Mission on Coronavirus Disease 2019 (COVID-19). Geneva: WHO; 2020 [cited 2020 Apr 28]. Available from: https://www.who. int/docs/default-source/coronaviruse/who-china-joint-mission-on-covid-19-final-report.pdf

11. Sanche S, Lin YT, Xu C, Romero-Severson E, Hengartner N, Ke R. The Novel Coronavirus, 2019$\mathrm{nCoV}$, is highly contagious and more infectious than initially estimated [preprint]. medRxiv. 2020. https://doi.org/10.1101/2020.02.07.20021154

12. Szwarcwald CL, Malta DC, Pereira CA, Vieira MLFP, Conde WL,Souza Júnior PRB, et al. [National Health Survey in Brazil: design and methodology of application]. Cienc Saude Coletiva. 2014;19(2):333-42. Portuguese. https://doi.org/10.1590/1413-81232014192.14072012

13. Instituto Brasileiro de Geografia e Estatística. Projeções da população: Brasil e unidades da federação: revisão 2018. Rio de Janeiro: IBGE; 2018.

14. Koma W, Neuman T, Claxton G, Rae M, Kates J, Michaud J. How many adults are at risk of serious illness if infected with Coronavirus? updated data. San Francisco (USA): Kaiser Family Foundation- KFF; 2020

15. GBD 2017 Causes of Death Collaborators. Global, regional, and national age-sex-specific mortality for 282 causes of death in 195 countries and territories, 1980-2017: a systematic analysis for the Global Burden of Disease Study 2017. Lancet. 2018;392(10159):1736-88. https://doi.org/10.1016/S0140-6736(18)32203-7

16. Imai N, Cori A, Dorigatti I, Baghelin M, Donnelly CA, Riley S, et al. Report 3: transmissibility of 2019-nCoV. London: Imperial College London; 2020. https://doi.org/10.25561/77148

17. Ferguson NM, Laydon D, Nedjati-Gilani G, Imai N, Ainslie K, Baguelin M, M, et al. Report 9: impact of non-pharmaceutical interventions (NPIs) to reduce COVID-19 mortality and healthcare demand. London: Imperial College London; 2020. https://doi.org/10.25561/77482

18. Centers for Disease Contol and Preventiion. Implementation of mitigation strategies for communities with local COVID-19 transmission. Atlanta, GA: CDC; 2020 [cited 2020 Apr 28]. Available from: https://www.cdc.gov/coronavirus/2019-ncov/downloads/community-mitigation-strategy.pdf

19. Ministério da Saúde (BR), Secretaria de Vigilância em Saúde, Departamento de Análise em Saúde e Vigilância de Doenças Não Transmissíveis. VIGITEL Brasil 2018: vigilância de fatores de risco e proteção para doenças crônicas por inquérito telefônico: estimativas sobre frequência e distribuição sociodemográfica de fatores de risco e proteção para doenças crônicas nas capitais dos 26 estados brasileiros e no Distrito Federal em 2018. Brasília, DF; 2019.

Authors' contribution: Study design and planning: LFMR, BT; Data collection, analysis and interpretation: LFMR, BT, MCS; Manuscript development or review: LFMR, BT, MCS, PRBSJ, CLS; Approval of the final version: LFMR, BT, MCS, PRBSJ, CLS; Public responsibility for the content of the article: LFMR.

Conflict of Interest: The authors declare no conflict of interest 